\title{
Synthesis and Evaluation of Mn-Fe Binary Oxide Adsorbents for Arsenic Removal
}

\author{
Jiefei Li, Mei Xue * \\ School of Chemistry and Chemical Engineering, Inner Mongolia University, 235 West University \\ Road, Hohhot, 010021, China \\ email: setsubai@sina.cn
}

Keywords: Adsorption; Arsenic; Metal oxide; Drinking water

\begin{abstract}
Mn-Fe binary oxide adsorbents are prepared by co-precipitation method for removal of arsenic from contaminated drinking water. Arsenic adsorption ability is influenced by $\mathrm{pH}$ of reaction solution and $\mathrm{Mn} / \mathrm{Fe}$ mole ratio. Adsorbent M/F4/6-12 with amorphous phase shows higher arsenic removal of $99.9 \%$. The adsorption isotherm followed Langmuir equation, indicating that it could effectively remove arsenic even from contaminated drinking water in which arsenic concentration is markedly low. The maximal adsorption capacity of As(III) and As(V) are 54.1 $\mathrm{mg} / \mathrm{g}$ and $49.5 \mathrm{mg} / \mathrm{g}$, respectively.
\end{abstract}

\section{Introduction}

Common arsenic species in environment include arsenate (As(V)), arsenite ( As(III)) , dimethylarsenic acid and monomethylarsenic acid [1]. Arsenite (As (III)) which is more toxic than arsenate (As (V)) is the dominant arsenic in ground water [2,3]. Many methods such as coagulation/precipitation, ion exchange, membrane filtration, and reverse osmosis have been used for arsenic removal [4,5] and arsenic adsorption removal is considered to be one of the most promising technologies because it is effective in the adsorption removal of low-concentration arsenic from liquids [6,7]. Up to now, several adsorbents have been reported by some authors. Zhi Mang $\mathrm{Gu}$ et al. have prepared granular activated carbon-based, iron-containing adsorbents [8]. Min Jang et al. have used hydrous ferric oxide incorporated into diatomite adsorbent for arsenic column application and shows higher arsenic adsorption speeds and adsorption capacities compared to AAFS-50 (that is known to be arsenic removal adsorbent in Bangladesh ) [9,10]. Gao Sheng zhang et al prepared a novel Mn-Fe binary oxide by co-precipitation method, which combined the oxidation property of manganese dioxide with the high adsorption feature to $\mathrm{As}(\mathrm{V})$ of iron oxides [11]. Above studies demonstrate that the iron oxide or/and manganese oxide have a strong affinity for arsenic. The suitable preparation conditions of Mn-Fe binary oxide adsorbents have not been reported yet. In this study we have prepared the Mn-Fe binary oxide by co-precipitation method and investigated the influence of adsorbent preparation conditions for arsenic adsorption ability, for example, $\mathrm{pH}$ of reaction solution, $\mathrm{Mn} / \mathrm{Fe}$ mole ratio and calcinations treatment of adsorbent.

\section{Experimental}

\section{Preparation of adsorbents}

Mn-Fe binary oxide: Manganese nitrate $\left(\left(\mathrm{Mn}\left(\mathrm{NO}_{3}\right)_{2}, 1 \mathrm{~mol} / \mathrm{L}\right)\right.$ and iron nitrate $\left(\mathrm{Fe}\left(\mathrm{NO}_{3}\right)_{3}, 1\right.$ $\mathrm{mol} / \mathrm{L}$ ) solution were mixed with $\mathrm{Mn} / \mathrm{Fe}$ mole ratio of 10/0, 8/2, 6/4, 4/6, 2/8, 0/10 for $20 \mathrm{~mL}$, and then added deionized water to $100 \mathrm{~mL}$. Desired amount of $\mathrm{NaOH}$ were dissolved in deionized water for $180 \mathrm{~mL}$. The metal nitrate solution and the alkaline solution were mixed, stirred for $5 \mathrm{~min}$ and aged for $12 \mathrm{~h}$, the formed suspension separated by centrifuge (7000 ppm, $10 \mathrm{~min})$ and washed 3 times with deionized water and dried at $40{ }^{\circ} \mathrm{C}$, get the Mn-Fe binary oxide. The adsorbent samples were designated as MF4/6-6.99, where MF corresponds to the Mn and Fe, 4/6 corresponds to the mole ratio of $\mathrm{Mn} / \mathrm{Fe}, 6.99$ corresponds to the $\mathrm{pH}$ value of reaction solution. 


\section{Adsorption experiments}

Adsorption experiments were performed by a batch method. All chemicals were analytical grade and were purchased from Kanto Chemical Co., Inc. (Osaka, Japan). The As(III) and As(V) stock solutions were prepared by diluting arsenic standard solution $100 \mathrm{ppm}\left(\mathrm{As}_{2} \mathrm{O}_{3} \cdot \mathrm{NaCl}(0.005 \%)\right.$, $\mathrm{HCl}$ acid solution) and $1000 \mathrm{ppm}\left(\mathrm{As}_{2} \mathrm{O}_{5} \cdot \mathrm{NaCl}(0.0005 \%), \mathrm{HCl}\right.$ acid solution) with ultra pure water, respectively. As(III) and As(V) stock solution (2 ppm, $\left.100 \mathrm{~cm}^{3}\right)$ and adsorbents (25 mg) were mixed in glass vessel and sealed with parafilm stirring for $22 \mathrm{~h}$ at room temperature. And then the arsenic concentration of the supernatant was analyzed by a Seiko inductively coupled plasma mass spectrometer (ICP-MS SPQ9000, < 2 ppm) and Seiko inductively coupled plasma atomic emission spectrometer (ICP-AES SPQ7800, $\geqq 2$ ppm).

\section{Adsorbent characterization}

The crystal structure of the adsorbents were investigated using a powder X-ray diffractometer (Rigaku type RINT2100) with $\mathrm{CuK} \alpha(\lambda=0.15418 \mathrm{~nm})$ radiation. TG-DTA curves of adsorbents were measured on a MAC Science Thermal Analyzer system (TG-DTA2000) at a heating rate of $10^{\circ} \mathrm{C} / \mathrm{min}$ in air. Nitrogen adsorption-desorption were carried out with a Quantachrome-type 1-C apparatus for adsorbents degassed at $120{ }^{\circ} \mathrm{C}$ for $2 \mathrm{~h}$. The morphology of the adsorbents were observed using Field Emission Scanning Electron Microscopy (FE-SEM) (JEOL, JSM-6700FZ). Infrared spectra (FT-IR) were obtained by $\mathrm{KBr}$ method on a Perkin-Elmer Infrared spectrometer (2000 series).

\section{Results and Discussion}

\section{Synthesis of Mn-Fe binary oxide adsorbents}

Adsorbents MF6/4 was prepared under different $\mathrm{pH}$ of reaction solution. The XRD patterns are shown in Figure 1. Amorphous phase was observed at $\mathrm{MF6} / 4-6.99, \mathrm{Mn}_{3} \mathrm{O}_{4}$ phase was observed at MF6/4-10.1 and MF6/4-12.3, which indicates that $\mathrm{pH}$ value of reaction solution higher than 10 is the most suitable preparation condition to achieve the manganese and iron oxide suspension. Adsorbents with different Mn/Fe mole ratio (10/0, 8/2, 6/4, 4/6, 2/8 and 0/10) were prepared at $\mathrm{pH}$ value of 12. The XRD patterns of the samples obtained are shown in Figure $2 . \mathrm{Mn}_{3} \mathrm{O}_{4}$ phase was observed in those adsorbents samples obtained by changing $\mathrm{Mn} / \mathrm{Fe}$ mole ratio from 10/0 to 6/4, $\alpha$-FeOOH phase was observed in those adsorbents samples obtained by changing $\mathrm{Mn} / \mathrm{Fe}$ mole ratio from $4 / 6$ to $0 / 10$.

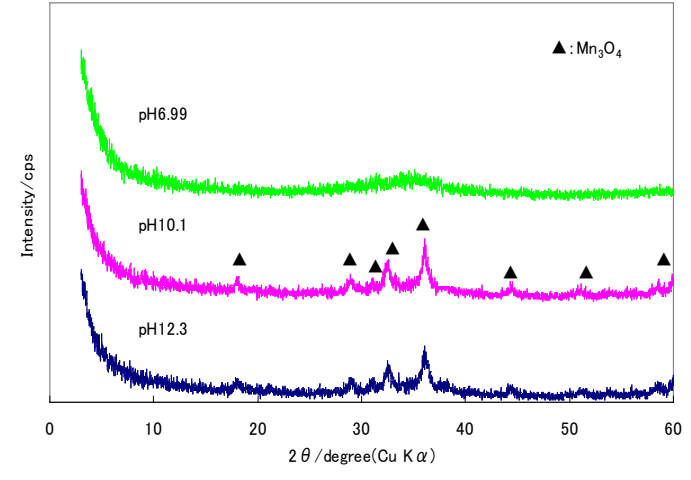

Figure 1. XRD patterns of Adsorbents MF6/4-0 were prepared under different $\mathrm{pH}$

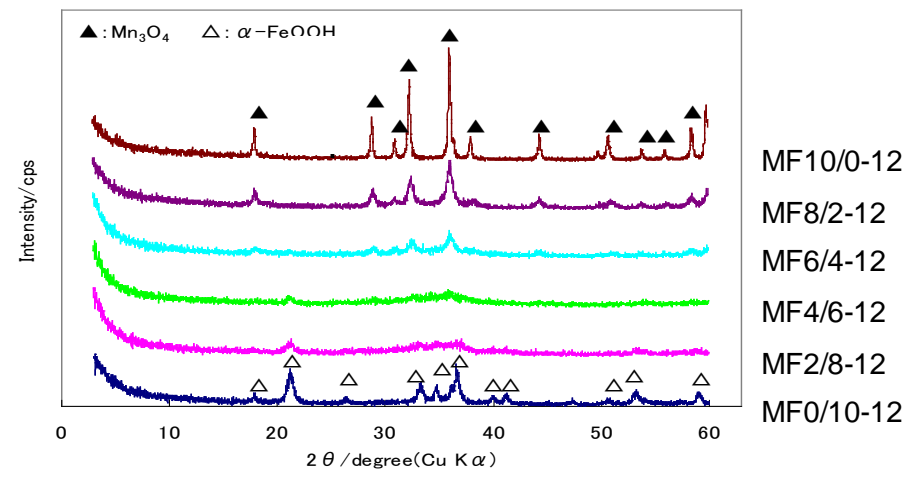

Figure 2. XRD patterns of Mn-Fe binary oxides with different $\mathrm{Mn} / \mathrm{Fe}$ mole ratio

The morphologies of adsorbents were investigated by using FE-SEM. MF10/0-12 $\left(\mathrm{Mn}_{3} \mathrm{O}_{4}\right.$ phase $)$ and MF0/10-12 ( $\alpha$-FeOOH phase) samples show fiber and needle like particle morphology with about $20 \mathrm{~nm}$ in diameter (Figure 3(a, c)). MF4/6-12 sample with amorphous structure shows aggregated small particles morphology (Figure 3 (b)). The result reveals that binary of Fe and $\mathrm{Mn}$ oxide, easy to achieve amorphous structure with higher surface area (Table 1). 


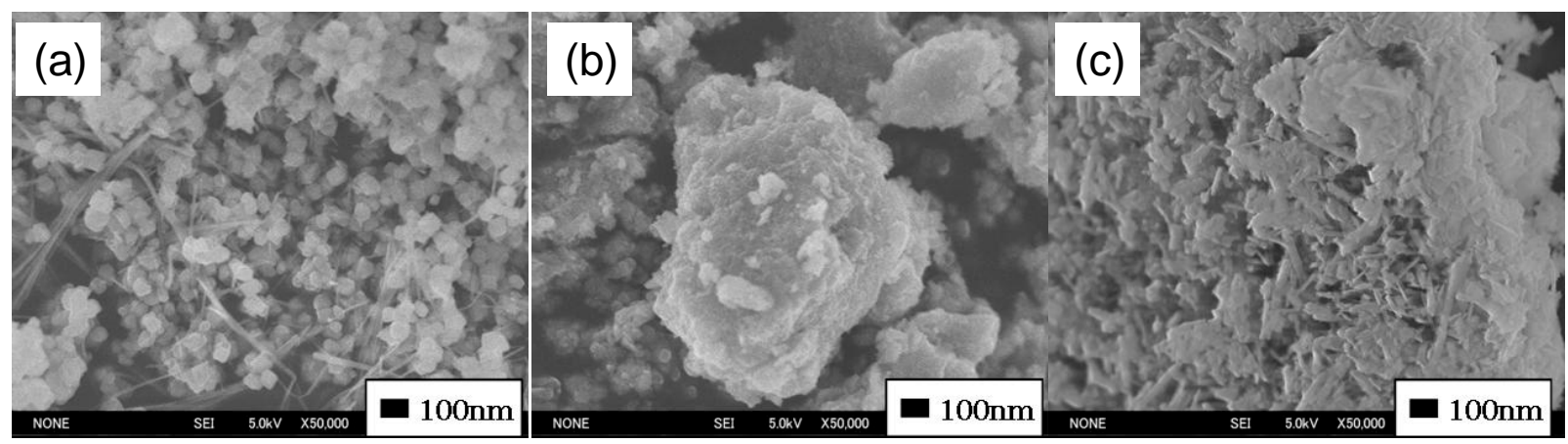

Figure 3. SEM photographs of (a) MF10/0-12, (b) MF4/6-12 , and (c) MF0/10-12

It is found in Table 1 that all the BET surface areas $\left(\mathrm{S}_{\mathrm{BET}}\right)$ of Mn-Fe binary oxide adsorbents are larger than Mn oxide (MF10/0-12) and Fe oxide (MF0/10-12) adsorbents, and MF4/6-12 with amorphous structure shows the highest $S_{\text {BET }}$ of $277 \mathrm{~m}^{2} / \mathrm{g}$. This is identical with the result observed by using FE-SEM and indicates that the crystallinity of adsorbents is decreased by the co-existing of $\mathrm{Fe}$ and $\mathrm{Mn}$ ion during the preparation process. After calcination of adsorbents at $350{ }^{\circ} \mathrm{C}$, BET surface area decreased slightly.

Table 1. BET surface area of adsorbents

\begin{tabular}{cc|c}
\hline \multirow{2}{*}{ Adsorbent } & \multicolumn{2}{c}{ BET $\left(\mathrm{m}^{2} / \mathrm{g}\right)$} \\
\cline { 2 - 3 } & Before calcination & After calcinations $\left(350^{\circ} \mathrm{C}\right)$ \\
\hline MF10/0-12 & 23 & 15 \\
MF8/2-12 & 136 & 99 \\
MF6/4-12 & 255 & 161 \\
MF4/6-12 & 277 & 189 \\
MF2/8-12 & 275 & 173 \\
MF0/10-12 & 166 & 68
\end{tabular}

The nitrogen adsorption/desorption isotherms of MF4/6-12 sample can be identified as BDDT type II which is characteristic of macro porous solids (Figure 4).

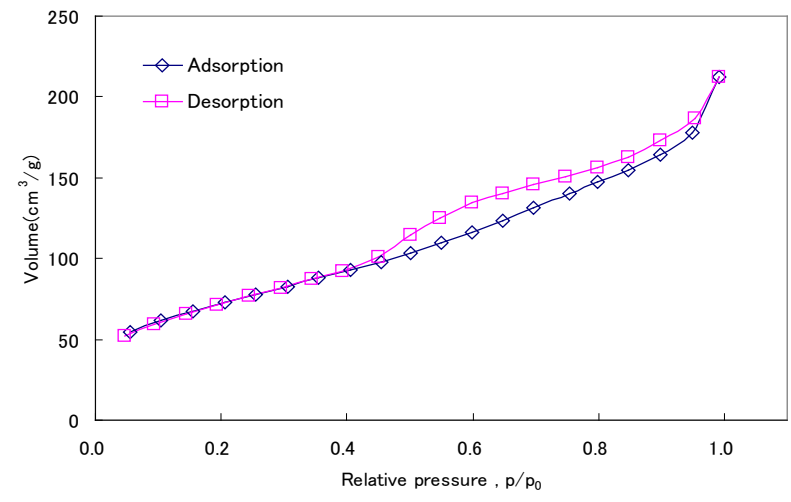

Figure 4. $\mathrm{N}_{2}$ adsorption isotherm at $77 \mathrm{~K}$ on $\mathrm{MF} 4 / 6-12$

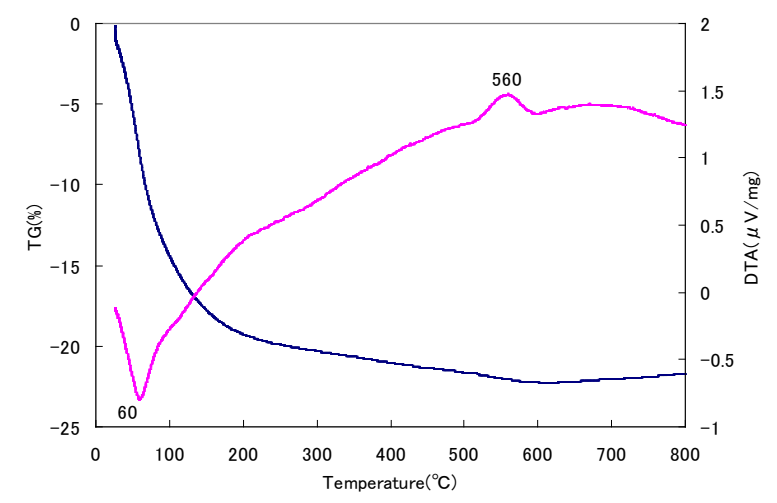

Figure 5. TG-DTA curves of MF4/6-12

The TG-DTA curves of MF4/6-12 samples are shown in Figure 5. The weight loss of MF4/6-12 at $60{ }^{\circ} \mathrm{C}$ accompany endothermic peak might be due to the dissipation of water adsorbed on the surface and weight loss in the range of around 100 to $400{ }^{\circ} \mathrm{C}$ to the dehydration of $a$-FeOOH to $\mathrm{Fe}_{2} \mathrm{O}_{3}$, exothermic peak at $560{ }^{\circ} \mathrm{C}$ not weight loss might be due to phase change from amorphous $\mathrm{Mn}_{2} \mathrm{O}_{3}$ to $\mathrm{Mn}_{3} \mathrm{O}_{4}$ by releasing $\mathrm{O}_{2}$ gas. Assume weight loss before $400{ }^{\circ} \mathrm{C}$ is loss of water, the moisture content in the adsorbent is $23 \%$.

\section{As(III) adsorption of Mn-Fe binary oxide adsorbents}

As(III) adsorption property of adsorbents with different $\mathrm{Mn} / \mathrm{Fe}$ mole ratio are shown in Table 3. Adsorbents with $\mathrm{Mn} / \mathrm{Fe}$ mole ratio from $8 / 2$ to $2 / 8$ show a high As(III) removal (> 99.8\%) compared with manganese (MF10/0-12, 75.1\%) and hydrated iron oxide (MF0/10-12, 98.6\%). 
As(III) adsorption property are also shown in Table 2. As(III) removal of above adsorbents was decreased after calcined at $350{ }^{\circ} \mathrm{C}$, which may be due to the facts: 1) As(III) affinity of oxygen iron hydroxide is stronger than iron oxide, 2) the $\mathrm{S}_{\mathrm{BET}}$ of adsorbents decreased.

Table 2. As(III) removal on Mn-Fe binary oxides

\begin{tabular}{cc|c}
\hline \multirow{2}{*}{ Adsorbent } & \multicolumn{2}{c}{ As(III) removal (\%) } \\
\cline { 2 - 3 } & Before calcination & After calcinations $\left(350^{\circ} \mathrm{C}\right)$ \\
\hline MF10/0-12 & 75.1 & 38 \\
MF8/2-12 & 99.9 & 81.9 \\
MF6/4-12 & 99.9 & 98.3 \\
MF4/6-12 & 99.9 & 96.4 \\
MF2/8-12 & 99.8 & 97.5 \\
MF0/10-12 & 98.6 & 28
\end{tabular}

Adsorbent $=25 \mathrm{mg}$, As(III) stock solution $=100 \mathrm{~cm}^{3}$, Conc. of As(III) $=2 \mathrm{ppm}$, Contact time $=22 \mathrm{~h}$.

\section{Adsorption isotherms}

Figure 6 showed the adsorption isotherms for $\mathrm{As}(\mathrm{III})$ and $\mathrm{As}(\mathrm{V})$ at room temperature of adsorbent MF4/6-12 with the highest As(III) removal of $99.9 \%$. The Langmuir equation is represented as a linear form (1):

$$
C_{\mathrm{e}} / q_{\mathrm{e}}=1 /\left(q_{\mathrm{m}} b\right)+C_{\mathrm{e}} / q_{\mathrm{m}}
$$

Where $C_{\mathrm{e}}$ : equilibrium concentration of As in solution $\left(\mu \mathrm{g} / \mathrm{dm}^{3}\right), q_{\mathrm{e}}$ : equilibrium uptake of As (mg/g), $q_{\mathrm{m}}$ : maximum adsorption capacity of As (mg/g), $b$ : adsorption constant $\left(\mathrm{dm}^{3} / \mathrm{mg}\right)$.

From the fitting of experimental data by plotting $C_{\mathrm{e}} / q_{\mathrm{e}}$ against $C_{\mathrm{e}}$, the saturation capacity $\left(q_{\mathrm{m}}\right)$ for the As(III) and As(V) adsorption were evaluated as $54.1 \mathrm{mg} / \mathrm{g}$ and $49.5 \mathrm{mg} / \mathrm{g}$, respectively. The adsorption constant $(b)$ for the As(III) and As(V) adsorption were evaluated as $2.4 \mathrm{dm}^{3} / \mathrm{mg}$ and 0.8 $\mathrm{dm}^{3} / \mathrm{mg}$, respectively, and correlation coefficient is 0.99 . Since the $b$ value reflects the strength of adsorption, the smaller $b$ value for $\mathrm{As}(\mathrm{V})$ suggests that $\mathrm{As}(\mathrm{V})$ interact weakly with adsorbent compared with As(III).

The Freundlich equation is represented as a linear form (2):

$$
q_{\mathrm{e}}=K C_{\mathrm{e}}{ }^{1 / n}
$$

Where $q_{\mathrm{e}}$ : As uptake (mg/g), $C_{\mathrm{e}}$ : equilibrium concentration of As in solution $\left(\mu \mathrm{g} / \mathrm{dm}^{3}\right)$, and $K$ $\left(\mathrm{dm}^{3} / \mathrm{mg}\right)$ : adsorption constant. Freundlich constant $n$ of As(III) and As(V) adsorption were 9.43 and 4.43, respectively. The $n>2$ and $K$ shows large value for As(III) and As(V) suggest that higher As removal can be obtained by using MF4/6-12 for a wide range of As concentration in solution, and slightly influenced by As concentration.

The experimental date fit with Langmuir isotherm. High regression coefficients $\left(\mathrm{R}^{2}>0.99\right)$ suggested that Langmuir models was suitable for describing the adsorption behavior of As(III) and As(V) on adsorbent MF4/6-12.
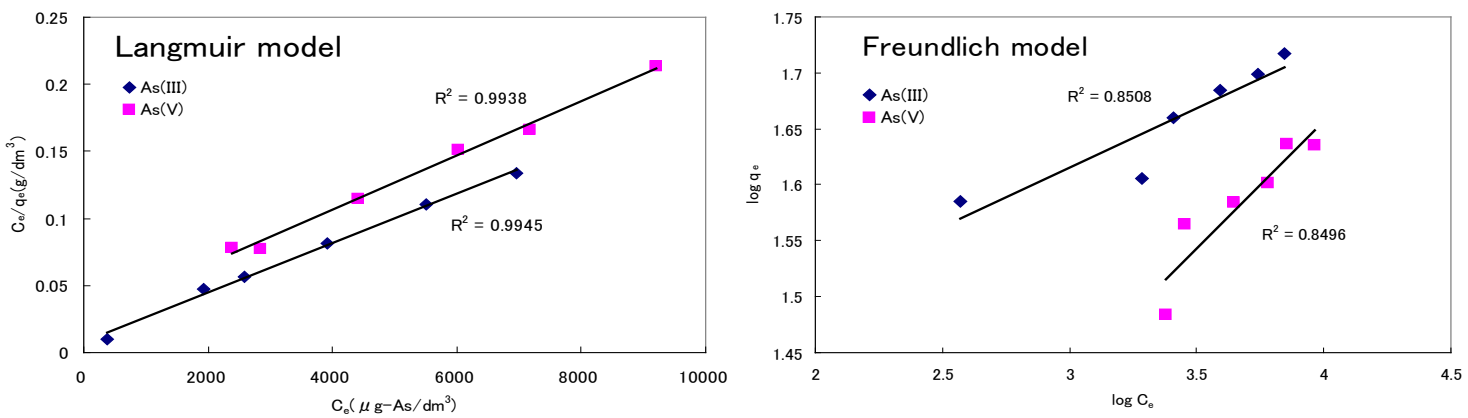

Figure 6. Langmir and Freundlich isotherm of MF4/6-12. Adsorbent: 25 mg, volume of As(III) or As(V) stock soltion: $100 \mathrm{~cm}^{3}$, concentration of $\mathrm{As}(\mathrm{III})$ and $\mathrm{As}(\mathrm{V}): 10 \sim 20 \mathrm{ppm}$, contact time: $24 \mathrm{~h}$

\section{Arsenic adsorption mechanism}

In order to study the arsenic adsorption mechanism, adsorbent (MF4/6-12) and (MF0/10-12) which before and after high concentration As(III) and As(V) adsorption were characterized by FT-IR (Figure 7). For MF4/6-12 (amorphous phase), the broad vibration band in the range of $3000-3500 \mathrm{~cm}^{-1}$ and vibration band at $1615 \mathrm{~cm}^{-1}$ correspond to $\mathrm{H}-\mathrm{O}$ stretching vibration and 
bending vibration of $\mathrm{H}_{2} \mathrm{O}$ respectively, vibration bands at $1050 \mathrm{~cm}^{-1}, 1340 \mathrm{~cm}^{-1}$ and $1500 \mathrm{~cm}^{-1}$ correspond to bending vibration of hydroxyl group (Fe-OH) and almost disappear after As adsorptions, a new band at $830 \mathrm{~cm}^{-1}$ appeared and can be assigned to the As-O stretching vibration. For MF0/10-12 ( $\alpha$-FeOOH phase), vibration bands at $1040 \mathrm{~cm}^{-1}, 1320 \mathrm{~cm}^{-1}$ and $1510 \mathrm{~cm}^{-1}$ corresponding to $\mathrm{O}-\mathrm{H}$ bending vibration of $\mathrm{FeO}(\mathrm{OH})$ almost disappear after As adsorption. For MF10/0-12 ( $\mathrm{Mn}_{3} \mathrm{O}_{4}$ phase), vibration bands at $620 \mathrm{~cm}^{-1}, 520 \mathrm{~cm}^{-1}$ can be assigned to the Mn-O stretching vibration. However, those vibration bands not changed before and after As(III) and As(V) adsorption. Above results indicate that $\mathrm{As}(\mathrm{III})$ and $\mathrm{As}(\mathrm{V})$ adsorption occurs through As-O-Fe chemical bond instead of As-O-Mn chemical bond at the surface of adsorbents. Adsorption mechanism of arsenic can be explained by the surface adsorption. As(III) and As(V) adsorption occurs through As-O-Fe chemical bond rather than As-O-Mn chemical bond on the surface of adsorbents.
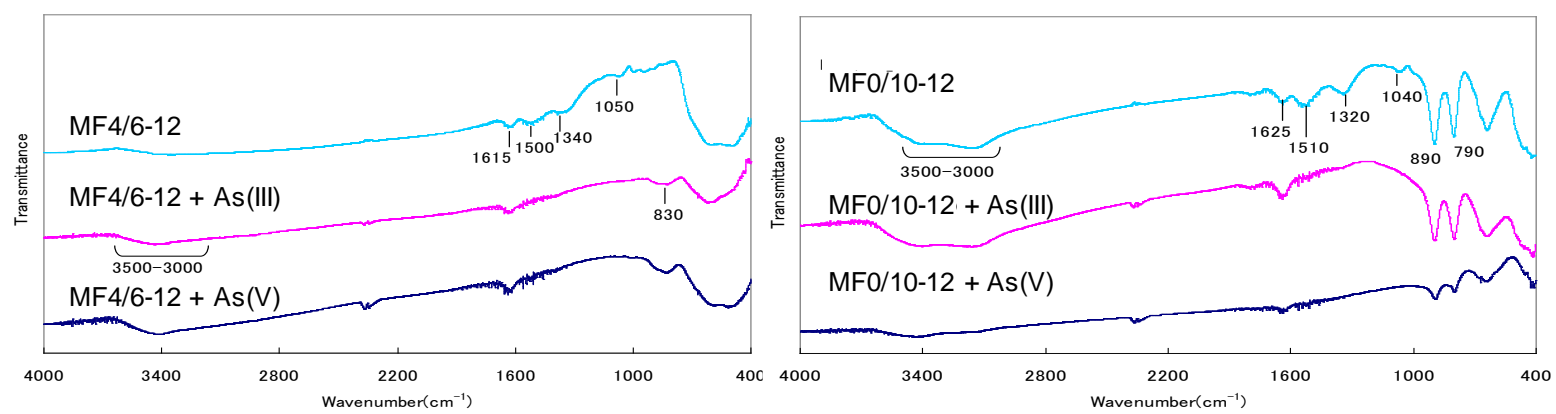

Figure 7. FT-IR spectra of adsorbents before and after As adsorption

\section{Conclusion}

Mn-Fe binary oxide has been prepared in order to arsenic removal by adsorption. The main phase of Mn-Fe binary oxide is influenced by synthesis conditions, e.g. $\mathrm{pH}$ of reaction solution, $\mathrm{Mn} / \mathrm{Fe}$ mole ratio and calcination treatment. MF4/6-12 with amorphous structure shows the highest As(III) removal of $99.9 \%$. Adsorption isotherm of MF4/6-12 shows that As uptake is slightly dependent on As concentration of stock solution and high As removal can be obtained. Maximum As adsorption capacity of MF4/6-12 is $54.1 \mathrm{mg} / \mathrm{g}$ for As(III) and $49.5 \mathrm{mg} / \mathrm{g}$ for As(V). IR spectra of MF4/6-12 indicate that As adsorption occurs on the surface of iron oxide instead of the surface of manganese oxide. This Mn-Fe binary oxide adsorbent could be a promising and low cost adsorbent used for As contaminated drinking water.

\section{Acknowledgment}

This study was supported by NSFC (No. 21266014) and Grant-in-Aid for Science Research (B) (No. 23350101) from the Japan Society for the Promotion of science.

\section{References}

[1]. X.C. Le, S. Yalcin, M.S. Ma, Speciation of submicrogram per liter levels of arsenic in water: on-site species separation integrated with sample collection [J]. Environmental Science Technology. 2000: 34(11): 2342-2347

[2]. P.L. Smedley, D.G. Kinniburgh, A review of the source, behavior and distribution of arsenic in natural waters [J], Appllied Geochemistry. 2002:17(5): 517-568

[3]. W.R. Penrose, Arsenic in the marine and aquatic environment: Analysis, occurrence and significance [J]. CRC Critical Reviews in Environmental Control. 1974: 4 (1-4): 465-482

[4]. L.S. McNeill, M. Edwards, Predicting arsenate removal during metal hydroxide precipitation [J]. Journal of American Water Works Association. 1997: 89(1): 75-86 
[5]. P. Brandhuber, G. Amy, “Alternative methods for membrane filtration of arsenic from drinking water [J]. Desalination. 1998: 117(1-3): 1-10

[6]. S.E. O'Relly, D.G. Strawn, D.L. Sparks, Residence time effects on arsenate adsorption/desorption mechanisms on goethite [J]. Soil Science Society of America Journal. 2001: 65(1): $67-77$

[7]. L. Dambies, Existing and prospective sorption technologies for the removal of arsenic in water [J]. Separation Science and Technology. 2004: 39(3): 603-627

[8]. Z.M. Gu, J. Fang, B.L. Deng, Preparation and evaluation of GAC-based iron-containing adsorbents for arsenic removal [J]. Environmental Science Technology. 2005: 39(10): 3833-3843

[9]. Alcan Chemicals (product data, AAFS-50); ALCAN Chemicals: Montreal, Canada. 1998.

[10] M. Jang, S.H. Min, T.H. Kim, J.K. Park, Removal of arsenite and arsenate using hydrous ferric oxide incorporated into naturally occuring porous diatomite [J]. Environmental Science Technology. 2006: 40(5): 1636-1643

[11] G.S. Zhang, J.H. Qu, H.J. Liu, R.P. Liu, G.T. Li, Removal mechanism of As(III) by a novel Fe-Mn binary oxide adsorbent: oxidation and sorption [J]. Environmetal Science Technology. 2007: 41(13) 4613-4619 